\title{
Peruvian volcanic ashes as new alternative material in geopolymer preparation: influence of dissolution concentration and wear resistance
}

\author{
Danny Tupayachy-Quispe, $\mathrm{Msc}^{1}$, Jonathan Almirón, $\mathrm{Msc}^{2}$, Fredy Apaza, $\mathrm{Lic}^{3}$, Rossibel Churata, Msc ${ }^{4}$, Evelyn \\ Paredes, $\mathrm{PhD}^{5}$, Manuel Torres-Carrasco, $\mathrm{PhD}^{6}$ and Asunción Bautista, $\mathrm{PhD}^{7}$ \\ ${ }^{1}$ Universidad Católica de Santa María, Perú, dtupayachy@ucsm.edu.pe \\ ${ }^{2,4}$ Universidad Nacional de San Agustín de Arequipa, Perú, jalmiron@unsa.edu.pe \\ ${ }^{3}$ Instituto Geológico, Minero y Metalúrgico, Perú, fapaza@ingemmet.gob.pe \\ ${ }^{5,6,7}$ Materials Science and Engineering Department. IAAB, Universidad Carlos III de Madrid, Spain, \\ eparedes@ing.uc3m.es, matorres@ing.uc3m.es, mbautist@ing.uc3m.es.
}

\begin{abstract}
This research focuses on the search for materials susceptible to being alkaline activated for the generation of new geopolymer materials (alternative to fly ash and blast furnace slag). The potential use of volcanic ash from the Ubinas volcano (located in Moquegua, Peru) for geopolymer synthesis has been studied. $\mathrm{NaOH}$ solution has been used in different concentrations for the activation of volcanic ashes. The effect of the concentration of the $\mathrm{NaOH}$ solution on the mechanical properties (compressive strength and porosity) of the hardened specimens has been analyzed. Systems activated with solutions of 6, 9 and 12M has shown a good mechanical performance due to the formation of the main reaction product $(N-A-S-H$ gel) and a good wear resistance. The efflorescence effect when using high alkali contents has affected the wear results. This research opens a new gate to the use of this type of materials of volcanic origin and their use as resistant materials to wear and abrasion.
\end{abstract}

Keywords- Volcanic ash; geopolymer; compressive strength; alkaline solution; wear durability.

\section{INTRODUCTION}

Ordinary Portland cement (OPC) is considered the principal construction material due to its good value for money. However, in the production process of this material there are a high-energy demand, the consumption of nonrenewable raw materials and the emission of greenhouse gases (essentially $\mathrm{CO}_{2}$ ) to the atmosphere [1,2]. The manufacturing of one ton of Portland cement produces around 0.8 tonnes of $\mathrm{CO}_{2}$ that is released into the atmosphere as a result of the raw material decomposition and emission of pollutants from the burning fuel. These problems associated to Portland cement production could be optimized by using alternative raw materials as complete or partial substitutes for clinker [3], which also could boost the economy of different communities by generating more alternatives and opportunities for growth.

On the other hand, alkali-activated materials (AAM) or geopolymers constitute an alternative to Portland cement [46]. In this sense, alkaline activation calls for two basic components: alkaline activator, such as $\mathrm{NaOH}$, sodium silicate (waterglass solution), etc [7-12] and amorphous or vitreous aluminosilicates. These aluminosilicates may be natural products (caolin, natural volcanic fly ash, etc) or

Digital Object Identifier (DOI):

http://dx.doi.org/10.18687/LACCEI2020.1.1.5

ISBN: 978-958-52071-4-1 ISSN: 2414-6390 industrial by-products (blast furnace slag or fly ash) [10,1316]. The reaction between the aluminosilicate and the activator generates a new material with similar or better properties than an OPC material. Some positive aspects of these alternative materials are: high mechanical strengths [17], low heat of hydration [18], higher durability to acidsulphate attack [19] and carbonation [20,21], resistance to high temperatures [22], resistance to freeze-thaw cycles [23] and resistance to corrosion [24-26], among others. These properties depend on various parameters such as the type of raw materials, the chemical and mineralogical composition of the aluminosilicate sources, the particle size of the raw material, the curing process, the composition of the alkaline solution and the liquid-solid ratio [27] .

However, over time, one of the main problems of alkaline activated material or geopolymers is the availability of different aluminosilicates (blast furnace slag or fly ash). For example, fly ash from thermal power plants has been a great source in the preparation of geopolymers in recent years. Nevertheless, due to the importance of renewable energies at present, thermal power plants will end up disappearing and therefore, will not generate so much fly ash in the future. That is why it is urgent to look for alternative sources of aluminosilicates that are susceptible to being activated.

Volcanic ashes are pyroclastic vitreous materials produced by violent eruptive volcanic action [28]; these materials can be found in countries with past or current volcanism, as it is the case of Peru. In recent years, several studies have been conducted about the use of volcanic ash (considered natural waste) as alternative material in the construction and engineering industry and applications $[29,30]$. These materials present a series of advantages in relation to the preparation of geopolymers, for instance, easy access in the regions where they are present (low economic cost) [31]. With regard to the factors that affect their reactivity, it is important to highlight that they have to present an amorphous phase [32], that the $\mathrm{SiO}_{2} / \mathrm{Na}_{2} \mathrm{O}$ ratio of the amorphous fraction around or below 4 provides better results [32], and finer grinding favor higher reactivity and strength [32]. Other observations of these volcanic ashes are the request of heat curing $\left(40-90^{\circ} \mathrm{C}\right)$ in order to achieve the reactivity and a good mechanical strength behavior [33]. However, there is a limited information available about the influence of different activator concentrations [34] and on the durability of these type of materials [33]. 
There are few studies on durability in these materials [33], especially in relation to wear tests on cementitious materials. The process of wear or abrasion is an important phenomenon to consider in this type of cementitious materials since its final application may be subject, for example, the use on roads or runways. Recent studies have shown that the effect of the addition of different nanoparticles $\left(\mathrm{SiO}_{2}\right)$ provides an increase in abrasion resistance in Portland cement systems $[35,36]$. However, in alternative materials to Portland cement (alkali-activated or geopolymer materials) there are no works on this type of durability. The use of fly ash and blast furnace slag have been used as aggregates in the preparation of concrete in several studies and its behavior against abrasion has been studied [37]. These results have shown that a natural aggregate alternative by slag leads to increase the abrasion resistance. Nevertheless, the question will be: what is the performance against abrasion in alkaline activated materials?

The south of Peru has eight active volcanoes located in the Central Volcanic Zone [38,39]. Among them, the Ubinas volcano $\left(16^{\circ} 22^{\prime} \mathrm{S}, 70^{\circ} 54^{\prime} \mathrm{W}\right.$; $5672 \mathrm{~m}$ above sea level) is the most active one in Peru, with a recurrence of four to seven unrest episodes per century. The activity of the Ubinas volcano has generated millions of tons of volcanic materials that cover large areas with deposits of a mafic andesitic composition [38]. The ashes can have an important impact on the arable lands of the towns near the volcano. This occurred during the last eruption in 2006-2009, affecting the approximately 4760 people living in the seven villages within $12 \mathrm{~km}$ of this volcano.

For that, the aim of the present research is to study the potential use of volcanic ash from the Ubinas volcano for the synthesis of geopolymers, as well as to examine the viability of their use as replacement for the cement used in construction. In addition, the use of different concentration of alkaline solutions has been evaluated during geopolymer synthesis and the wear durability test was studied in these new alternative materials. This study opens a new possibility for the use of volcanic ash in the preparation of new alternative materials with a good wear durability behavior as its use as pavements or prefabricated materials.

\section{EXPERIMENTAL SECTION}

\subsection{Materials}

The chemical composition of the volcanic ash was analyzed with an Inductively Coupled plasma mass spectrometry (ICP-MS) equipment. Table 1 shows the chemical composition of the volcanic ashes used in this study from the deposit at the base of the Ubinas volcano (Moquegua, Peru). The main oxides are compromised $\mathrm{SiO}_{2}$, $\mathrm{Al}_{2} \mathrm{O}_{3}$ and $\mathrm{Fe}_{2} \mathrm{O}_{3}$ with a $\mathrm{SiO}_{2} / \mathrm{Al}_{2} \mathrm{O}_{3}$ molar ratio of 3.96. This composition is suitable for its use as a raw material for the synthesis of geopolymers, since it is in the range of the basic ingredients for raw materials necessary for synthesis of geopolymers [12,33].
The particle size analysis of the dried and ground volcanic ash was carried out using a Malvern MASTERSIZER 2000 Laser Light Scattering Particle Sizer Analyzer. The volcanic ash, with an average particle size of $3 \mathrm{~mm}$, was dried at 105 ${ }^{\circ} \mathrm{C}$ for $6 \mathrm{~h}$ in an electric furnace (see Figure 1a). It was then ground in a Fritsch $6 \mathrm{~S}$ planetary mill for $25 \mathrm{~min}$ at $450 \mathrm{rpm}$ using stainless steel balls to reduce the particle size of the ash until obtaining a fine powder. Figure $1 \mathrm{~b}$ shows the particle size distribution of ground volcanic ash, being the main metrics used to describe distributions $\mathrm{d}_{10}=2.4 \mu \mathrm{m}, \mathrm{d}_{50}=25.9$ $\mu \mathrm{m}$ and $\mathrm{d}_{90}=57.4 \mu \mathrm{m}$. The density of particle size distribution (blue curve) shows that volcanic ash dust from Ubinas has a bimodal distribution. The first mode varies from 0.3 to $12 \mu \mathrm{m}$ and the second from 12 to $100 \mu \mathrm{m}$, with an average particle size of $27.39 \mu \mathrm{m}$ for the ground ash. The specific surface area was of $2.29 \mathrm{~m}^{2} / \mathrm{g}$. In addition, $\mathrm{NaOH}$ (Panreac analytical grade $98 \%$ sodium hydroxide) solution was used at different concentrations in molar.

Table 1. Chemical composition (wt. \%) of volcanic ash used in this study $\begin{array}{lllllllllllll}\text { Oxide } & \mathrm{LOI}^{*} & \mathrm{SiO}_{2} & \mathrm{Al}_{2} \mathrm{O}_{3} & \mathrm{Fe}_{2} \mathrm{O}_{3} & \mathrm{CaO} & \mathrm{MgO} & \mathrm{K}_{2} \mathrm{O} & \mathrm{Na}_{2} \mathrm{O} & \mathrm{P}_{2} \mathrm{O}_{5} & \mathrm{MnO} & \mathrm{TiO} & \end{array}$ \begin{tabular}{|llllllllllll|}
\hline Volcanic ash & 0.87 & 58.7 & 14.8 & 7.69 & 5.8 & 4.17 & 2.63 & 3.52 & 0.37 & 0.1 & 1.14 \\
\hline
\end{tabular} *LOI= loss on ignition
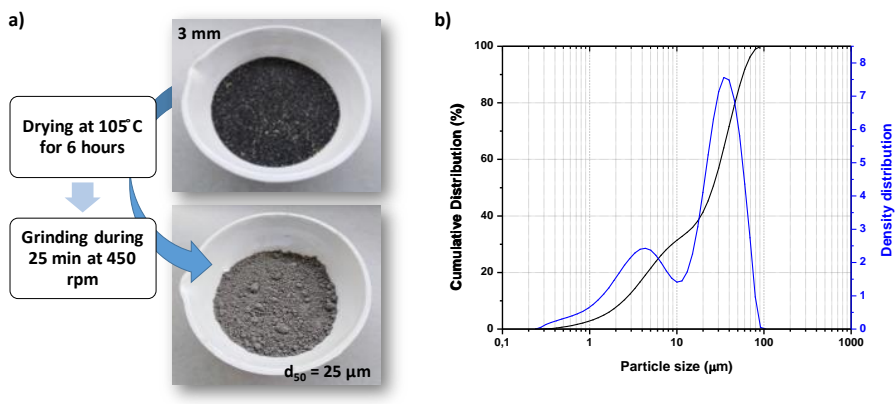

Figure 1. a) scheme of the thermal treatment and grinding used to obtain the volcanic ash with a particle size $\mathrm{d}_{50}=25.88 \mu \mathrm{m}$; b) particle size distribution of the volcanic ash.

\subsection{Geopolymer synthesis and trials conducted}

The geopolymer pastes were prepared by alkaline activation of the volcanic ash according to the conditions given in Table 2. The liquid/solid ratio in geopolymers was 0.2 in all system. Each paste was mixed according to the standard UNE-196-3. The resulting pastes were then poured into cylindrical molds ( $28 \mathrm{~mm}$ diameter), followed by compacting in a press with up to $15 \mathrm{MPa}$. This decreases the amount of alkaline solution used, which represents the costliest aspect in obtaining geopolymers. The test specimens were immediately demolded, covered with plastic film and cured with temperature $\left(80^{\circ} \mathrm{C}\right)$ during $48 \mathrm{~h}$ in an oven. The pastes were chamber-cured $(>90 \%$ relative humidity at $20 \pm 2^{\circ} \mathrm{C}$ ) for different ages until testing day. CEM IV pastes were prepared as reference with a $\mathrm{L} / \mathrm{S}=0.35$. In all cases, the workability was the same that recommended in European standard EN 196-3. 
Table 2. Pastes prepared and activation conditions

\begin{tabular}{cccc}
\hline System & Activator & $\mathrm{L} / \mathrm{S}$ & Curing temperature $\left({ }^{\circ} \mathrm{C}\right)$ \\
\hline CEM IV & $\mathrm{H}_{2} \mathrm{O}$ & 0.35 & Room temperature \\
AAVA-N6 & $\mathrm{NaOH} 6 \mathrm{M}$ & 0.2 & 80 \\
AAVA-N8 & $\mathrm{NaOH} 8 \mathrm{M}$ & 0.2 & 80 \\
AAVA-N9 & $\mathrm{NaOH} \mathrm{9M}$ & 0.2 & 80 \\
AAVA- & $\mathrm{NaOH}$ & 0.2 & 80 \\
N12 & $12 \mathrm{M}$ & & \\
AAVA- & $\mathrm{NaOH}$ & 0.2 & 80 \\
N14 & $14 \mathrm{M}$ & & 80 \\
AAVA- & $\mathrm{NaOH}$ & 0.2 & \\
N16 & $16 \mathrm{M}$ & & \\
\hline
\end{tabular}

The compressive strength of the samples was determined at the age of 7, 14, 28, 60 and 90 days according to the recommendations of the EN 12390-3 Standard in an Automatic Compression Testing Machine (ELE International, England) with a displacement rate of 10 $\mathrm{mm} / \mathrm{min}$. The result was the average of 5 replicated samples.

The mineralogical phases of the volcanic ash and the synthetized geopolymers were identified through the Bruker $\mathrm{X}$-ray diffractometer model D8 Advance Davinci with $\mathrm{CuK} \alpha$ radiation source $(\lambda=0.1542 \mathrm{~nm})$. The conditions selected to obtain diffraction patterns included a voltage of $40 \mathrm{kV}$ and a current of $40 \mathrm{~mA}$, carried out at a $2 \theta$ range between $10^{\circ}$ and $80^{\circ}$ with a scanning speed of $2 \% \mathrm{~min}$. The FTIR spectra of the volcanic ash and the synthetized geopolymers were measured in a Perkin Elmer Spectrum GX FT-IR spectrometer system with Spectrum software v2:00. The samples were prepared by the $\mathrm{KBr}$ pellet procedure. The thermogravimetric analysis of the volcanic ash and the geopolymers was carried out with a Perkin Elmer Simultaneous Thermal Analyzer with a cooling system (STA 6000 model), in a nitrogen environment with a flow of $20 \mathrm{ml} / \mathrm{min}$, from room temperature to $900{ }^{\circ} \mathrm{C}$ at a heating rate of $10{ }^{\circ} \mathrm{C} / \mathrm{min}$. The wear resistance was determined in a Microtest machine according to the recommendations of the ASTM G99-03 standard using a 6 $\mathrm{mm}$ diameter stainless steel ball (AISI 316-G100), applying a weight of $15 \mathrm{~N}$ at $60 \mathrm{rpm}$ (see Figure 2).
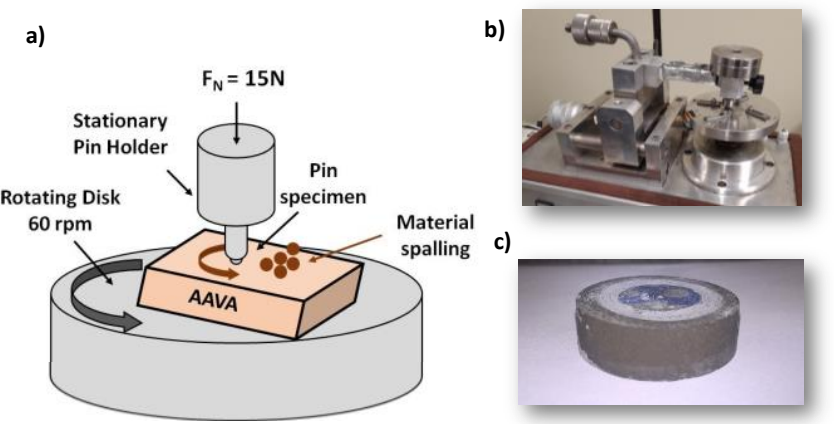

Figure 2. a) Scheme of the pin-on-disc wear test performed in each of the samples analyzed; b) Microtest machine used for the wear test; c) footprint image marked on the AAVA sample.

\section{RESULTS AND DISCUSSION}

\subsection{Physical and mechanical properties}

\footnotetext{
Digital Object Identifier: (only for full papers, inserted by LACCEI). ISSN, ISBN: (to be inserted by LACCEI).
}

Figure 3 a shows the evolution of the mechanical resistance to the geopolymers synthetized by alkaline activation using the $\mathrm{NaOH}$ solution at different concentrations after 28 days of curing. As the concentration of activator increases, it is observed an increase in the values of compression resistance, reaching values around $64 \mathrm{MPa}$ when using a concentration of $14 \mathrm{M} \mathrm{NaOH}$. This compressive strength with a concentration of $14 \mathrm{M}$ is comparable to the geopolymers obtained from fly ash and kaolin [40], while the compression resistance of hardened volcanic ash mortar at $8 \mathrm{M}$ is greater than the Portland cement mortars [41]. These results indicate that keeping the rest of the working variables constant, the mechanical resistances of activated volcanic ash geopolymers are enhanced by increasing the activator concentration up to $14 \mathrm{M}$. The alkali content reaches a certain value (which depends on the type of mineral, the type of activator and the curing condition), beyond which there is no significant additional increase in strength. In fact, increasing the concentration of the activator involves raising the $\mathrm{pH}$ of the medium and increasing the $\mathrm{Na}_{2} \mathrm{O}$ content in the system. This favors the dissolution of the starting ash particles and the precipitation of the alkaline aluminosilicate gel (N-A-S-H gel) [40], a compound responsible for the cementing properties of these materials and therefore responsible for the mechanical behavior [4]. Thus, Figure $3 \mathrm{a}$ and $3 \mathrm{~b}$ show the enormous influence of $\mathrm{NaOH}$ concentrations on the increase of the compression resistance of the mortars.
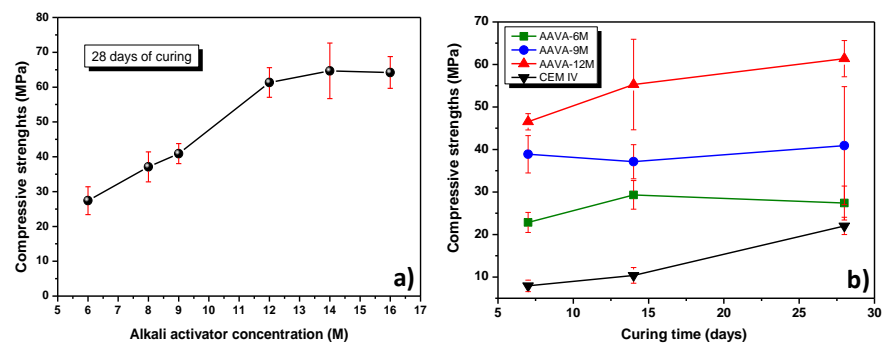

Figure 3. Mechanical properties of alkali-activated volcanic ash pastes. a) Compressive strengths at 28 days of curing of the different pastes activated with different concentration solutions $(6,8,9,12,14$ and $16 \mathrm{M})$; b) Compressive strengths at 7,14 and 28 days of curing for the alkaliactivated volcanic ash with $\mathrm{NaOH} 6 \mathrm{M}$ (AAFA-N6), NaOH 9M (AAFAN9), $\mathrm{NaOH} 12 \mathrm{M}$ (AAFA-N12) and CEM IV.

The resistance of the volcanic ash-based geopolymer mortars in relation to time is depicted in Figure 3b, where it is shown that strength considerably increases for all cases from 7 days $(22,39$, and $46 \mathrm{MPa}$ for mixtures at 6,9 and $12 \mathrm{M}$ respectively) to 28 days $(27,41$, and $61 \mathrm{MPa})$. The highest compressive strength value for geopolymers was $61.4 \mathrm{MPa}$ at 28 days and a concentration of $12 \mathrm{M}$, with this result being favorably compared to those generated from volcanic ash [28,32]. The results were also compared with type IV cement specimens manufactured under the same conditions as the geopolymers, where the resistance obtained at 28 days of curing was $37.6 \mathrm{MPa}$, which is lower than geopolymers at 9 and $12 \mathrm{M} \mathrm{NaOH}$. The concentration of the alkaline solution in the synthesis of geopolymers from volcanic ash plays an important role in the formation and densification of the gel, as Sindhunata observed [42]. However, according to Xu and Deventer [43], damaging characteristics such as efflorescence and brittleness may arise due to the increase of the free alkali content in the product. Therefore, for

18 $^{\text {th }}$ LACCEI International Multi-Conference for Engineering, Education, and Technology: "Engineering, Integration, and Alliances for a Sustainable Development" "Hemispheric Cooperation for Competitiveness and Prosperity on a Knowledge-Based Economy", 29-31 July 2020, Buenos Aires, Argentina. 3 
comparative purposes, the effect of $\mathrm{NaOH}$ concentration (6, 9 and $12 \mathrm{M}$ ) on properties of geopolymers was evaluated (see Figure $3 \mathrm{~b}$ ). The total porosity of the different volcanic ash pastes shows a behavior according to the mechanical results obtained. Table 3 shows how, as the concentration of $\mathrm{NaOH}$ increases, there is a decrease in the total porosity and the water absorption content, indicating that a more compact and dense gel is being formed which provides better mechanical benefits. Table 3 shows the apparent and real bulk density of the hardened geopolymer pastes at 28 days. The density of the cured pastes increases as the concentration of the alkaline solution also does. Moreover, it is obvious that density decreases as porosity increases and vice versa.

Table 3. Physical properties (apparent density, real density, total porosity and water absorption) of the geopolymer pastes at 28 curing-days with different alkaline concentration (6M, 9M and $12 \mathrm{M})$

\begin{tabular}{|cccccc|}
\hline System & Activator & $\begin{array}{c}\text { Apparen } \\
\text { t density } \\
\left(\mathrm{g} / \mathrm{cm}^{3}\right)\end{array}$ & $\begin{array}{c}\text { Real } \\
\text { density } \\
\left(\mathrm{g} / \mathrm{cm}^{3}\right)\end{array}$ & $\begin{array}{c}\text { Total } \\
\text { porosity } \\
(\%)\end{array}$ & $\begin{array}{c}\text { Water } \\
\text { absorpti } \\
\text { on }(\%)\end{array}$ \\
\hline AAVA-N6 & $\mathrm{NaOH} 6 \mathrm{M}$ & 1.78 & 2.71 & 36.4 & 17.8 \\
AAVA-N9 & $\mathrm{NaOH} 9 \mathrm{M}$ & 1.81 & 2.76 & 34.3 & 16.7 \\
AAVA-N12 & $\mathrm{NaOH} 12 \mathrm{M}$ & 1.88 & 2.79 & 30.7 & 14.6 \\
\hline
\end{tabular}

\subsection{Characterization of reaction products}

The FTIR spectra for the anhydrous volcanic ash and the 28-days geopolymer pastes are shown in Figure 4. The spectrum of the anhydrous volcanic ash shows three broad bands characteristic of the internal vibration of silicates. The band at ca. $1060 \mathrm{~cm}^{-1}$ is associated with the asymmetric vibrations of the $\mathrm{T}-\mathrm{O}$ bonds $(\mathrm{T}=\mathrm{Si}$ or $\mathrm{Al})$. The band that appears towards ca. $457 \mathrm{~cm}^{-1} \mathrm{~cm}$ is related to the deformation vibrations of the $\mathrm{Si}-\mathrm{O}-\mathrm{Si}$ bonds. The band that appears between ca. $780-790 \mathrm{~cm}^{-1}$ corresponds to the vibrations $v(\mathrm{Si}-$ O-Si). Finally, the band at ca. $547 \mathrm{~cm}^{-1}$ corresponds to the vibrations of octahedral aluminum [34].

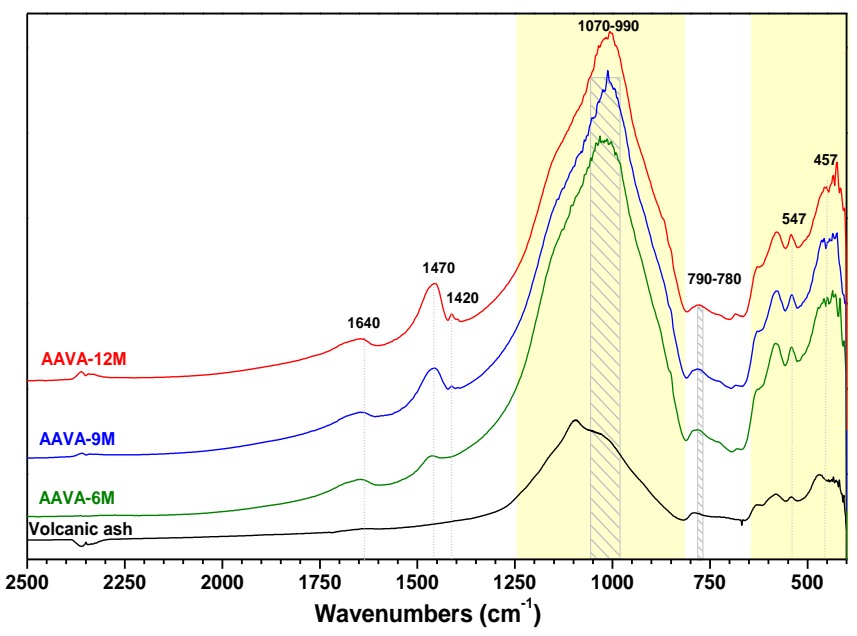

Figure 4. FTIR spectra for the anhydrous volcanic ash and 28-days geopolymer pastes activated with $\mathrm{NaOH} 6 \mathrm{M}$ (AAVA-N6), $\mathrm{NaOH} 9 \mathrm{M}$ (AAVA-N9) and NaOH 12M (AAVA-N12).

In Figure 4, the spectra (curves 6M, 9M and 12M) clearly show the effect that the highly alkaline medium exerts on the starting ash, that is: a large part of the vitreous phase of the ash dissolves in alkaline medium to precipitate later in form

Digital Object Identifier: (only for full papers, inserted by LACCEI). ISSN, ISBN: (to be inserted by LACCEI). of aluminosilicate gel (N-A-S-H gel). This occurs due to the shift that is observed in the vibration band of the T-O bonds between ca. 990 and ca. $1070 \mathrm{~cm}^{-1}$. In all systems, a shift of the main band occurs towards lower wavenumbers. The exact position of this band depends on the $\mathrm{Si} / \mathrm{Al}$ ratio of the reaction products formed. The displacement towards lower wavenumber is due to an increase in tetrahedral aluminum content [44]. This displacement of the observed band is more intense as the solution used has a higher concentration (AAVA-12M), indicating of a greater dissolution of the silicon coming from the volcanic ash and, therefore, a N-A$\mathrm{S}-\mathrm{H}$ gel richer in silicon is formed $[16,45,46]$. The appearance of some sharp bands indicates the formation of crystalline phases. The band around $1640 \mathrm{~cm}^{-1}$ arises from the water molecules, which are absorbed or trapped on the surface of the large cavities of the polymeric frame and observed mainly in ash activated with alkali because of the bending vibrations (H-O-H), including aluminosilicate networks [47]. The band around $1430-1420 \mathrm{~cm}^{-1}$ in the geopolymers is attributed to the stretching vibrations of the O-C-O bond that could be the result of the atmospheric carbonation of the unreacted high alkaline aqueous phase, which diffuses on the surface of the geopolymeric materials [48]. The relatively strong peaks observed at $\sim 1002 \mathrm{~cm}^{-1}$ (as well as $\sim 458 \mathrm{~cm}^{-1}$ ) in the alkaliactivated ashes are assigned to long-chain bonds and / or to the excess of formed Al-Si gel [47].
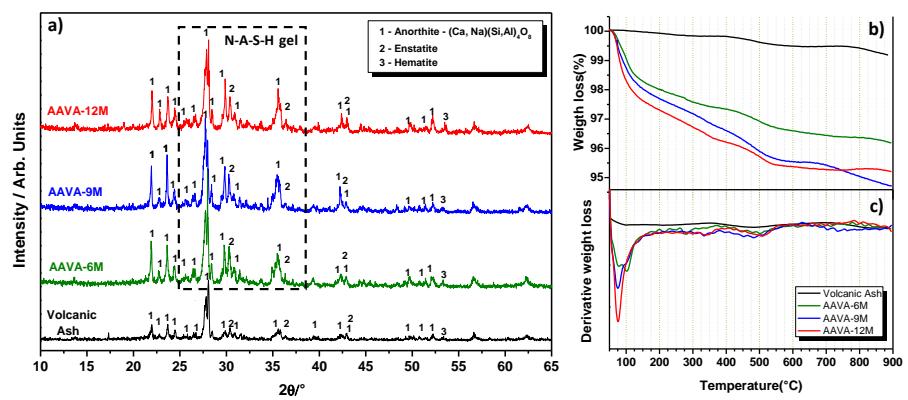

Figure 5. a) XRD diffractogram of raw volcanic ash and the different geopolymer pastes activated with $\mathrm{NaOH} 6 \mathrm{M}$ (AAVA-6M), $\mathrm{NaOH} 9 \mathrm{M}$ (AAVA-9M) and $\mathrm{NaOH} 12 \mathrm{M}$ (AAVA-12M); b) thermogravimetric curve of raw volcanic ash and the different geopolymer pastes; and c) derivative weight loss of the different pastes activated with different concentrations of $\mathrm{NaOH}$.

The diffractograms corresponding to the activated volcanic ash with the different concentrations of $\mathrm{NaOH}$ and the anhydrous volcanic ash are present in Figure 5. In the diffractogram, a crystalline phase is observed corresponding to feldspar $\mathrm{Na}\left(\mathrm{Ca}\left(\mathrm{Al}_{2} \mathrm{Si}_{2} \mathrm{O}_{8}\right)\right.$ and anorthite, although enstatite $\left(\mathrm{MgSiO}_{3}\right)$ and hematite $\left(\mathrm{Fe}_{2} \mathrm{O}_{3}\right)$ were also detected in small amounts. As a consequence of the activation process of the ash, there are changes in the peak intensity, and the area under the curve between $2^{\circ}$ and $38^{\circ}(2 \Theta)$ shows values of 1734 for the starting ash, 1457 for the materials at $6 \mathrm{M}$ of alkaline solution, 1493 for $9 \mathrm{M}$ and 1543 for $12 \mathrm{M}$. In addition, it is observed in all cases (regardless of the concentration used) that the diffractogram of the volcanic ash is slightly modified: the halo attributed to the vitreous phase of the starting volcanic ash moves slightly towards values higher than $2 \Theta$ $\left(2 \Theta=25-40^{\circ}\right)$. This modification is indicative of the formation of an alkaline aluminosilicate gel (N-A-S-H gel), the main reaction product. The minority phases detected in

18 $^{\text {th }}$ LACCEI International Multi-Conference for Engineering, Education, and Technology: "Engineering, Integration, and Alliances for a Sustainable Development" "Hemispheric Cooperation for Competitiveness and Prosperity on a Knowledge-Based Economy", 29-31 July 2020, Buenos Aires, Argentina. 4 
the starting material remain unchanged after being activated with the $\mathrm{NaOH}$ solution with the different concentrations.

The thermal behavior of the starting volcanic ash and the geopolymers is presented in Figure 5b. In the starting volcanic ash curve, there is no significant weight loss, being less than $1 \%$ up to $900{ }^{\circ} \mathrm{C}$. The geopolymers obtained at 6,9 and $12 \mathrm{M}$ of alkaline solution also have small mass losses ranging between 3.5 and $5.5 \%$. In the DTG curves of all the geopolymers samples $(6,9$ and $12 \mathrm{M})$, the weight loss is observed in two stages. The first weight loss is below $120^{\circ} \mathrm{C}$, with maximum values at 75 and $100{ }^{\circ} \mathrm{C}$, characteristics of the water loss physically adsorbed within the geopolymer matrix. The second weight loss is between 400 and $550{ }^{\circ} \mathrm{C}$ corresponding to the loss of chemically bound water contained in the geopolymer structure [34]. The total weight loss of the geopolymer samples obtained with different concentrations of alkaline solution is 3.2, 5.3 and 4.8\% for 6 , 9 and $12 \mathrm{M}$, respectively. The water contained in the geopolymer structure comes from the water that is consumed during the dissolution of the aluminosilicate raw materials to form aluminate and the silicate species and remains after condensation. At the same time, the water contained in the pores or physically bound to the matrix is related to the water released during the condensation between aluminate and silicate or water that has not participated in the dissolution of aluminosilicate [34].

\subsection{Activator concentration influence in wear resistance}

The ASTM G99-03 standard was used to calculate the wear rate (see Figure 5). The results are depicted in Figure 6. In Figure 6a, a notable decrease in wear is observed when the concentration of the alkaline solution increases. This behavior is consistent with the compressive strength and total porosity observed in Figure $2 \mathrm{c}$, where the resistance and porosity increase as the molar concentration of $\mathrm{NaOH}$ increases. This would indicate that there is a better reaction with a higher content of $\mathrm{NaOH}$ and therefore, the mechanical properties increase, and the wear is lower. As can be seen in Figure 6a, the best wear results occurred in alkaline activated systems or geopolymers, regardless of the concentration of the activator used. However, it is observed that the best results are obtained when using a solution of $9 \mathrm{M} \mathrm{NaOH}$ $\left(0.07 \times 10^{-5} \mathrm{~mm}^{3} / \mathrm{N} \cdot \mathrm{mm}\right)$, being the difference with respect to a CEM IV $\left(6.62 \times 10^{-5} \mathrm{~mm}^{3} / \mathrm{N} \cdot \mathrm{mm}\right)$ around $98 \%$ after 28 curing days. When using a $12 \mathrm{M} \mathrm{NaOH}$ solution, the wear of this system compared to a conventional cement is also lower (approximately 81\%). Nevertheless, an increase in activator concentration from $9 \mathrm{M}$ to $12 \mathrm{M}$ causes a decrease of wear performance. One of the main reasons is because activated systems with high concentrations of alkalis generate an efflorescence problem. This phenomenon occurs due to the combination of external agents such as humidity, presence of soluble substances and evaporation, in such a way that the substances that are going to form a light layer come to the surface. In this way, the samples prepared with $12 \mathrm{M} \mathrm{NaOH}$ solution favors the formation of a light surface layer, which, by means of the wear test, will be removed from the tested material, thus decreasing the mass of the test piece, and

Digital Object Identifier: (only for full papers, inserted by LACCEI). ISSN, ISBN: (to be inserted by LACCEI). therefore, higher wear values are obtained (a worse resistance to wear). This behavior can also be explained fr om the coefficient of friction values existing in each system. In Figure 6b, it is observed how the CEM IV and AAVA-6M samples showed very similar and relatively friction coefficients during the material testing, indicative that this homogeneous material do not stand nice the wear. A track is easily formed, and abrasion starts from nearly the beginning. However, the friction coefficients in samples AAVA-9M and AAVA-12M were very low, around 0.15 , The sample of volcanic ash activated with $9 \mathrm{M} \mathrm{NaOH}$ remained constant throughout the trial, while the sample AAVA-12M, after a distance traveled of $80 \mathrm{~m}$ experienced an increase in the coefficient of friction, reaching equal to the samples CEM IV and AAVA-6M. This behavior is due to the fact that during the test of this sample, the layer of material formed superficially due to the efflorescence is taken from the sample and introduced between the alumina ball and the material, thus generating a greater friction in the system with a worse slip between the ball and the material.
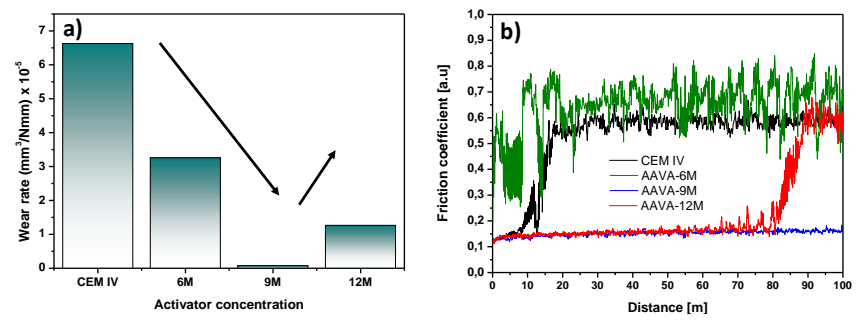

Figure 6. a) Wear behavior in the different materials tested (CEM IV and geopolymer pastes activated with $\mathrm{NaOH}$ at different concentrations); b) friction coefficient obtained for each of the evaluated systems.

\section{CONCLUSIONS}

To conclude, the manufacture of geopolymers from ashes proceeding from the Ubinas volcano was satisfactory. The use of these materials from regions rich in volcanic material can be an alternative to the use of materials commonly used for alkaline activation and/or geopolymer formation (such as fly ash, metakaolin, blast furnace slag, etc), due to its chemical composition rich in $\mathrm{SiO}_{2}, \mathrm{Al}_{2} \mathrm{O}_{3}, \mathrm{CaO}$ and $\mathrm{Na}_{2} \mathrm{O}$, making them susceptible to being alkaline activated, generating reaction products similar to when a fly ash is activated (N-A-S-H gel) and with a good mechanical and durable behavior.

The use of sodium hydroxide as an alkaline activator caused a high mechanical performance in short periods, while the compressive strength of the synthesized geopolymers suggests a possible application in construction. The $\mathrm{OH}$ concentration from the alkaline solutions plays an essential role in the dissolution stage of the silica and the reactive aluminum of volcanic ashes. The durability against the wear of these alkaline activated volcanic ashes with different concentration supposes an increase of the resistance up to $80 \%$ in comparison with a CEM IV. The use of high concentration of $\mathrm{NaOH}$ not only favors the results of mechanical strengths, also the formation of light superficial layer due to the efflorescence. The formation of this efflorescence layer affects the materials in terms of wear tests.

18 $^{\text {th }}$ LACCEI International Multi-Conference for Engineering, Education, and Technology: "Engineering, Integration, and Alliances for a Sustainable Development" "Hemispheric Cooperation for Competitiveness and Prosperity on a Knowledge-Based Economy", 29-31 July 2020, Buenos Aires, Argentina. 5 


\section{ACKNOWLEDGEMENTS}

The Instituto Geológico, Minero y Metalúrgico INGEMMET (INGEMMET) and Universidad Carlos III de Madrid. We also wish to express our gratitude to Juan Jose Camacho Torres and the researcher Francisco Javier Velasco López for their contributions.

\section{REFERENCES}

[1] Huntzinger, D.N., Eatmon, T.D.:A life-cycle assessment of Portland cement manufacturing: comparing the traditional process with alternative technologies, J. Clean. Prod. 17, 668-675, (2009)

[2] Rehan, R., Nehdi, M.: Carbon dioxide emissions and climate change: policy implications for the cement industry, Environ. Sci. Policy. 8 , 105-114, (2005)

[3] Schneider, M., Romer, M., Tschudin, M., Bolio, H.: Sustainable cement production-present and future, Cem. Concr. Res. 41, 642650, (2011)

[4] Shi, C., Jiménez-Fernández A., Palomo A.: New cements for the $21^{\text {st }}$ century: The pursuit of an alternative to Portland cement, Cem. Concr. Res. 41. 750-763, (2011)

[5] Bernal, S.A., Provis, J. L.: Durability of Alkali-Activated Materials Progress and Perspectives, J. Am. Ceram. Soc. 97, 997-1008, (2014)

[6] Duxson, P., Fernández-Jiménez, A., Provis, J. L., Lukey, G. C., Palomo, A., Deventer, J. S. J.: Geopolymer technology: the current state of the art, J. Mater. Sci. 42, 2917-2933, (2006).

[7] Abdalqader, A.F., Jin, F., Al-Tabbaa A.: Development of greener alkali-activated cement: Utilisation of sodium carbonate for activating slag and fly ash mixtures, J. Clean. Prod. 113, 66-75, (2016)

[8] Huseien, G.F., Mirza, J., Ismail, M, Hussin, M.W.: Influence of different curing temperatures and alkali activators on properties of GBFS geopolymer mortars containing fly ash and palm-oil fuel ash, Constr. Build. Mater. 125, 1229-1240, (2016)

[9] Torres-Carrasco, M., Palomo, J.G., Puertas, F.: Sodium silicate solutions from dissolution of glass wastes: Statistical analysis, Mater. Construcción. 64 (2014).

[10] Torres-Carrasco, M., Rodríguez-Puertas, C., Alonso, M.M., Puertas, F.: Alkali activated slag cements using waste glass as alternative activators. Rheological behaviour, Boletín La Soc. Española Cerámica y Vidr. 54, 1-13, (2015)

[11] Puertas, F., Torres-Carrasco M., Alonso, M.M.: Reuse of urban and industrial waste glass as novel activator for alkali-activated slag cement pastes: a case study, in: Handb. Alkali-Activated Cem. Mortars Concr., pp. 75-110, (2014)

[12] Torres-Carrasco, M., Puertas, F.: Alkaline Activation of Aluminosilicates As an Alternative To Portland Cement: a Review, Rev. Rom. Mater. 47, 3-15, (2017)

[13] Neupane, K.: Fly Ash and GGBFS Based Powder-Activated Geopolymer Binders: A Viable Sustainable Alternative of Portland Cement in Concrete Industry, Mech. Mater. 103, 110-122, (2016)

[14] Palomo, A., Jiménez-Fernández, A., López-Hombrados, C., Lleyda, J.J.: Precast elements mado of alkali-activated fly ash concrete, in: V.M. Malhotra (Ed.), Int. Conf. Fly Ash, Silica Fume, Slag Nat. Pozzolans Concr., USA, (2004).

[15] Skavara, F., Jilek, T., Kopecky, L.: Geopolymer materials based on fly ash, 49, 195-204, (2005)

[16] Torres-Carrasco, M., Puertas, F.: Waste glass in the geopolymer preparation. Mechanical and microstructural characterisation, J. Clean. Prod. 90, 397-408, (2015)

[17] Glukhovsky, V., Zaitsev, Y., Pakhomow, V.: Slag-alkaline cements and concretes structures, properties, technological and economic aspects of the use, Silic. Ind. 48, 197-200, (1983)

[18] Davidovits, J.: Geopolymer Chemistry and Applications, Institud Géopolymère, San Quintin, France, (2008).

[19] Hossain, M.M., Karim, M.R., Hossain, M.M., Islam, M.N., Zain, M.F.M.: Durability of mortar and concrete containing alkali-activated binder with pozzolans: A review, Constr. Build. Mater. 93, 95-109, (2015)

[20] Bernal, S.A., Provis, J., Brice, D., Kilcullen, A., Duxson, P., Van Deventer, P.: Accelerated carbonation testing of alkali-activated binders significantly underestimates service life: The role of pore

Digital Object Identifier: (only for full papers, inserted by LACCEI).

ISSN, ISBN: (to be inserted by LACCEI). solution chemistry, Cem. Concr. Res. 42, 1317-1326, (2012)

[21] Bernal, S.A., San Nicolas, R., Provis, J.L., Mejía de Gutiérrez, R., Van Deventer, J.S.J.: Natural carbonation of aged alkali-activated slag concretes, Mater. Struct. 47, 693-707, (2013)

[22] Bernal, S. A., Mejía de Gutiérrez, R., Ruiz, F., Quiñones, H., Provis, J.L.: Desempeño a temperaturas altas de morteros y hormigones basados en mezclas de escoria/metacaolín activadas alcalinamente, Mater. Construcción. 62, 471-488, (2012)

[23] Torres-Carrasco, M., Tognonvi, M., Tagnit-Hamou, M., Puertas, F.: Durability of Alkali-Activated Slag Concretes Prepared using waste glass as Alternative activator, ACI. 112, 791-800, (2015)

[24] Fernández-Jiménez, A., Miranda, J.M., González, J.A., Palomo, A. Steel passive state stability in activated fly ash mortars, Mater. Construcción. 60, 51-65, (2010)

[25] Criado, M., Bernal, S.A., Garcia-Triñanes, P., Provis, J.L.: Influence of slag composition on the stability of steel in alkali-activated cementitious materials, J. Mater. Sci. 53, 5016-5035, (2018)

[26] Criado, M.: The corrosion behaviour of reinforced steel embedded in alkali-activated mortar, in: F. Pacheco-Torgal, J.A. Labrincha, C. Leonelli, A. Palomo, P. Chindaprasirt (Eds.), Handb. Alkali-Activated Cem. Mortars Concr., Woodhead Publishing series in civil and structural engineering, (2014).

[27] Shi, C., Krivenko, P., Roy, D.: Alkali-Activated Cements and Concretes, Taylor and Francis, London and New York, (2006).

[28] Lemougna, P.N., Chinje Melo, U.F., Delplancke, M.P., Rahier, H.: Influence of the chemical and mineralogical composition on the reactivity of volcanic ashes during alkali activation, Ceram. Int. 40, 811-820, (2014)

[29] Lemougna, P.N., Tuo Wang, K., Tang, Q., Nzeukou, A.N., Billong, N., Melo, U.C., Mn Cui, X.: Review on the use of volcanic ashes for engineering applications, Resour. Conserv. Recycl. 137, 177-190, (2018)

[30] Robayo-Salazar, R.A., Mejía de Gutiérrez, R.: Natural volcanic pozzolans as an available raw material for alkali-activated materials in the foreseeable future: A review, Constr. Build. Mater. 189,109118, (2018)

[31] Leonelli, C., Kamseu, E., Boccaccini, D.N., Melo, U.C. Rizzuti1, A., Billong, N., Miselli, P.: Volcanic ash as alternative raw materials for traditional vitrified ceramic products, Adv. Appl. Ceram. 106, 135141, (2007)

[32] Djon Li Ndjock, B.I., Elimbi, A., Cyr, M.: Rational utilization of volcanic ashes based on factors affecting their alkaline activation, J. Non. Cryst. Solids. 463, 31-39, (2017)

[33] Djobo, J.N.Y., Elimbi, A., Tchakouté, H.K., Kumar, S.: Volcanic ashbased geopolymer cements/concretes: the current state of the art and perspectives, Environ. Sci. Pollut. Res. 24, 4433-4446, (2017)

[34] Djobo, J.N.Y., Elimbi, A., Tchakouté, H.K., Kumar, S.: Reactivity of volcanic ash in alkaline medium, microstructural and strength characteristics of resulting geopolymers under different synthesis conditions, J. Mater. Sci. 51, 10301-10317, (2016)

[35] Ghoddousi, P., Shirzadi Javid, A.,A, Zareechian, M., Habibnejad Korayem M.: Physical and chemical effects of siliceous particles at nano, micro, and macro scales on properties of self-consolidating mortar overlays, Constr. Build. Mater. 189,1140-1154, (2018)

[36] Haruehansapong, S.,. Pulngern, P., Chucheepsakul, S.: Effect of Nanosilica Particle Size on the Water Permeability, Abrasion Resistance, Drying Shrinkage, and Repair Work Properties of Cement Mortar Containing Nano-SiO ${ }_{2}$, Adv. Mater. Sci. Eng. 2017, 1-11, (2017)

[37] Lam, M.N.T., Le, D.H., Jaritngam, S.: Compressive strength and durability properties of roller-compacted concrete pavement containing electric arc furnace slag aggregate and fly ash, Constr. Build. Mater. 191, 912-922, (2018)

[38] Thouret, J.C., Rivera, M., Wörner, G., Gerbe, M.C., Finizola, A., Fornari, M., Gonzales, K.: Ubinas: The evolution of the historically most active volcano in southern Peru, Bull. Volcanol. 67, 557-589, (2005)

[39] Moussallam, Y., Tamburello, G., Peters, N., Apaza, G., Schipper, C.I., Curtis, A., Aiuppa, A.,Masias, P., Boichu, M., Bauduin, S., Barnie, T., Bani, P.,. Giudice, G., Moussallam, M.: Volcanic gas emissions and degassing dynamics at Ubinas and Sabancaya volcanoes; implications for the volatile budget of the central volcanic zone, J. Volcanol. Geotherm. Res. 343, 181-191, (2017)

[40] Palomo, A.F.A. Factors affecting early compressive strength of alkali activated fly ash (OPC-free) concrete, Mater. Construcción. 57, 7-22, (2007)

[41] Ghrici, M., Kenai, S., Said-Mansour, M.: Mechanical properties and

18 $^{\text {th }}$ LACCEI International Multi-Conference for Engineering, Education, and Technology: "Engineering, Integration, and Alliances for a Sustainable Development" "Hemispheric Cooperation for Competitiveness and Prosperity on a Knowledge-Based Economy", 29-31 July 2020, Buenos Aires, Argentina. 6 
durability of mortar and concrete containing natural pozzolana and limestone blended cements, Cem. Concr. Compos. 29, 542-549, (2007)

[42] Sindhunata, J.S.J. Van Deventer, G.C., Lukey, Xu, F.: Effect of curing temperature and silicate concentration on fly-ash-based geopolymerization, Ind. Eng. Chem. Res. 45, 3559-3568, (2006)

[43] Xu, H., Van Deventer, J.S.J.: The geopolymerisation of aluminosilicate minerals, Int. J. Miner. Process. 59, 247-266, (2000)

[44] Fernández-Jiménez, A., Palomo, A.: Mid-infrared spectroscopic studies of alkali-activated fly ash structure, Microporous Mesoporous Mater. 86, 207-214, (2005)

[45] Mozgawa, W., Sitarz, M., Rokita, M.: Spectroscopic studies of different aluminosilicate structures, J. Mol. Struct. 511-512, 251-257, (1999)

[46] Kovalchuk, G., Fernández-Jiménez, A., Palomo, A.: Alkali-activated fly ash. Relationship between mechanical strength gains and initial ash chemistry, Mater. Construcción. 58, 35-52, (2008)

[47] Zaharaki, D., Komnitsas, K., Perdikatsis, V.: Use of analytical techniques for identification of inorganic polymer gel composition, J. Mater. Sci. 45, 2715-2724, (2010)

[48] Lemougna, P.N., MacKenzie, K.J.D., Melo, U.F.C.: Synthesis and thermal properties of inorganic polymers (geopolymers) for structural and refractory applications from volcanic ash, Ceram. Int. 37, 30113018, (2011)

Digital Object Identifier: (only for full papers, inserted by LACCEI). ISSN, ISBN: (to be inserted by LACCEI).

$1^{\text {th }}$ LACCEI International Multi-Conference for Engineering, Education, and Technology: "Engineering, Integration, and Alliances for a Sustainable Development" "Hemispheric Cooperation for Competitiveness and Prosperity on a Knowledge-Based Economy", 29-31 July 2020, Buenos Aires, Argentina. 7 